Analyse des Herrn Dr. O. La uenstein, Hannover, staatlich geprüfter Nahrungsmittel-Chemiker.

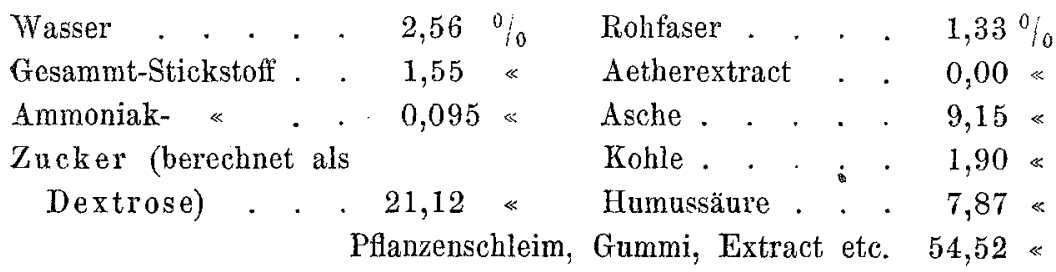

Hannover, im August 1901.

\title{
Zur Bestimmung von Kupfer in Kiesen.
}

$$
\begin{gathered}
\text { (Briefliche Mittheilung.) } \\
\text { Von }
\end{gathered}
$$

\section{Herbert Haas.}

Ich glaube schwerlich, dass die von Herrn O. Heidenreich im ersten Heft dieses Jahrganges ${ }^{1}$ ) angegebene Probe zur Bestimmung von Kupfer in Kiesen durch Fällung mit Aluminium und nachfolgende Elektrolyse für den metallurgischen Chemiker grossen Werth haben kann, da es in Kupferhütten (wenigstens in den Vereinigten Staaten) hauptsächlich auf Schnelligkeit ankommt.

Ich habe gerade so exacte Resultate erhalten (Heidenreich's Methode bis zur Fällung des Kupfers durch Aluminium befolgend), indem ich das gewaschene gefällte Kupfer in wenigen Tropfen Salpetersäure auflöste, filtrirte und dann die gewöhnliche Titration mit Cyankalium anwandte. Wenn man die Kupferlösung in Cylinder bringt und die Säule gegen weissen Grund (Porzellan) hält, so bekommt man sehr exacte Resultate und in kürzerer Zeit.

Laboratorium der Melczer Mining Co. El Copete, Sonora, Mexico, 22. September 1901.

1) Diese Zeitschrift 40, 15. 